\title{
Immobilization-induced hyperphosphatemia: successful therapy with biphosphonates
}

\author{
Duminda Suraweera*, Soma Wali, Funmilola Fashola and Nasser Mikhail \\ Department of Medicine, Olive-View Medical Center, Sylmar, California, USA
}

\section{Background}

Hypercalcemia is a well-known complication of immobilization as result of increased bone resorption [1]. Yet, immobilization associated with hyperphosphatemia and normocalcemia is rare and poorly understood.

\section{Purpose}

To describe an immobilized patient with hyperphosphatemia, normocalcemia treated successfully with pamidronate.

\section{Case report}

A 54-year-old man with history of traumatic brain injury several months earlier was referred to our hospital. On presentation, patient was noted to have an elevated serum phosphorous of $5.3 \mathrm{mg} / \mathrm{dl}$ (normal: 2.4-4.7 mg/dl), persistently high-normal total serum calcium levels [range 9.3-10.0 mg/dl, normal: 8.9-10.3 mg/dl], normal ionized calcium [range 5.1-5.4 mg/dl, normal: 4.8-5.6 mg/dl], normal renal function, suppressed levels of parathyroid hormone $(\mathrm{PTH}) 7 \mathrm{pg} / \mathrm{m}$ [normal: 15$65 \mathrm{pg} / \mathrm{ml}$ ] and 1,25 di-hydroxy vitamin $\mathrm{D}<8 \mathrm{pg} / \mathrm{ml}$ [normal: $18-72$ $\mathrm{pg} / \mathrm{ml}$. Body stores of vitamin $\mathrm{D}$ were adequate as reflected by normal serum 25 -hydroxy vitamin D [38.1 ng/ml, normal 30-96 ng/ml]. Urine phosphate was $960 \mathrm{mg} / 24 \mathrm{~h}$ [normal: $360-1600 \mathrm{mg} / 24 \mathrm{~h}$ ]. Trials of lowphosphate diet and chelating agent calcium acetate were not effective in lowering serum phosphate. On hospital day 30, pamidronate $30 \mathrm{mg}$ was given intravenously. Patient's serum phosphorous and PTH levels normalized 48 hours later (Figure 1).

\section{Discussion}

Hyperphosphatemia in presence of normocalcemia during immobilization is rarely described. Only 6 patients were previously reported. Among 14 immobilized subjects, Stewart et al. [2] found 5 patients having hyperphosphatemia, and 13 patients had high-normal serum calcium levels. Bachelder et al. [3] reported a man immobilized from burn injury with markedly elevated serum phosphorus of $8.1 \mathrm{mg} /$ $\mathrm{dl}$, but normal serum ionized calcium of $4.8 \mathrm{mg} / \mathrm{dl}$.

The mechanisms of immobilization-induced hyperphosphatemia are unclear. We believe hyperphosphatemia may be due to increase phosphorus release from bone as result of excess bone resorption coupled with decreased phosphorus urinary excretion. The latter effect may be caused by PTH suppression [4]. Indeed, Stewart et al. [2] documented elevation of renal phosphorus threshold in their patients. In our case, although urine phosphate excretion was normal, it may be regarded as "inappropriate" in the face of the prevailing hyperphosphatemia, Reasons of PTH suppression are also unclear. It is possible that in some patients, PTH is "hyper-sensitive" and becomes suppressed in response to rising levels of circulating calcium released from excess bone resorption even if serum calcium levels are still within normal range. In support of this hypothesis the finding that inhibition of bone resorption by pamidronate normalized PTH in parallel to drop of serum calcium to the low-normal or slightly low range (Figure 1).

The severe suppression of 1,25 di-hydroxy vitamin D in our patient and in patients of Stewart et al. [2] is likely due to PTH suppression because PTH enhances conversion of 25-hydroxy vitamin D to 1,25-di-hydroxy vitamin D [4]. Since accelerated bone resorption is the main underlying cause of hypercalcemia and/or hyperphosphatemia during immobilization, use of biphosphonates in this setting seems the most plausible therapy. Bachelder et al. [3] were the first to treat hyperphosphatemia in an immobilized patient with small dose pamidronate $30 \mathrm{mg}$, and reported normalization of serum phosphorus and PTH 14 days later. In another immobilized patient with mild hypercalcemia [serum calcium $10.4 \mathrm{mg} / \mathrm{dl}$ ] and severe hyperphosphatemia [serum phosphorus $6.5 \mathrm{mg} / \mathrm{dl}$ ], Trivedi et al. [5] used alendronate $70 \mathrm{mg}$ orally once weekly with normalization of serum phosphorus, calcium and PTH 3 weeks later. In our patient, we chose to use pamidronate for its rapid onset and long duration of action (Figure 1). Serum phosphorus normalized after 48 hours, remained normal for 23 days, then started to rise again reaching $4.8 \mathrm{mg} / \mathrm{dl}$ by the $24^{\text {th }}$ day after pamidronate therapy, the discharge day (Figure 1). Pamidronate administration can be repeated every 3-5 weeks if needed for recurrent hyperphosphatemia.

\section{References}

1. Maynard FM (1986) Immobilization hypercalcemia following spinal cord injury. Arch Phys Med Rehabil 67: 41-44. [Crossref]

2. Stewart AF, Adler M, Byers CM, Segre GV, Broadus AE (1982) Calcium homeostasis in immobilization: an example of resorptive hypercalcemia. New Engl J Med 306 1136-1140. [Crossref]

3. Bachelder VD, Muehlstedt, Smith CL (2001) Hyperphosphatemia in a burn patient. $J$ Burn Care Rehabil 22: 187-189. [Crossref]

4. Juppner H, Brown EM, Kronenberg HM (1999) Parathyroid hormone. In: Favus MJ (Ed.), Primer on the metabolic bone diseases and disorders of mineral metabolism. (4thedn), 80-87.

5. Trivedi DD, Gosmanova EO, Wall BM (2014) Immobilization-induced hyperphosphatemia and functional hypoparathyroidism successfully treated with ora bisphosphonates. Am J Med Sci 348: 179-180. [Crossref]

Correspondence to: Duminda Suraweera, MD, 14445 Olive View Dr, Los Angeles, California 91342, USA, Tel: (818)-364-3205; E-mail: suraweerad@gmail.com

Received: February 13, 2017; Accepted: February 23, 2017; Published: February 25,2017 


\section{Calcium, Phosphorous and Parathyroid Hormone Levels During Hospitilization}

12

10

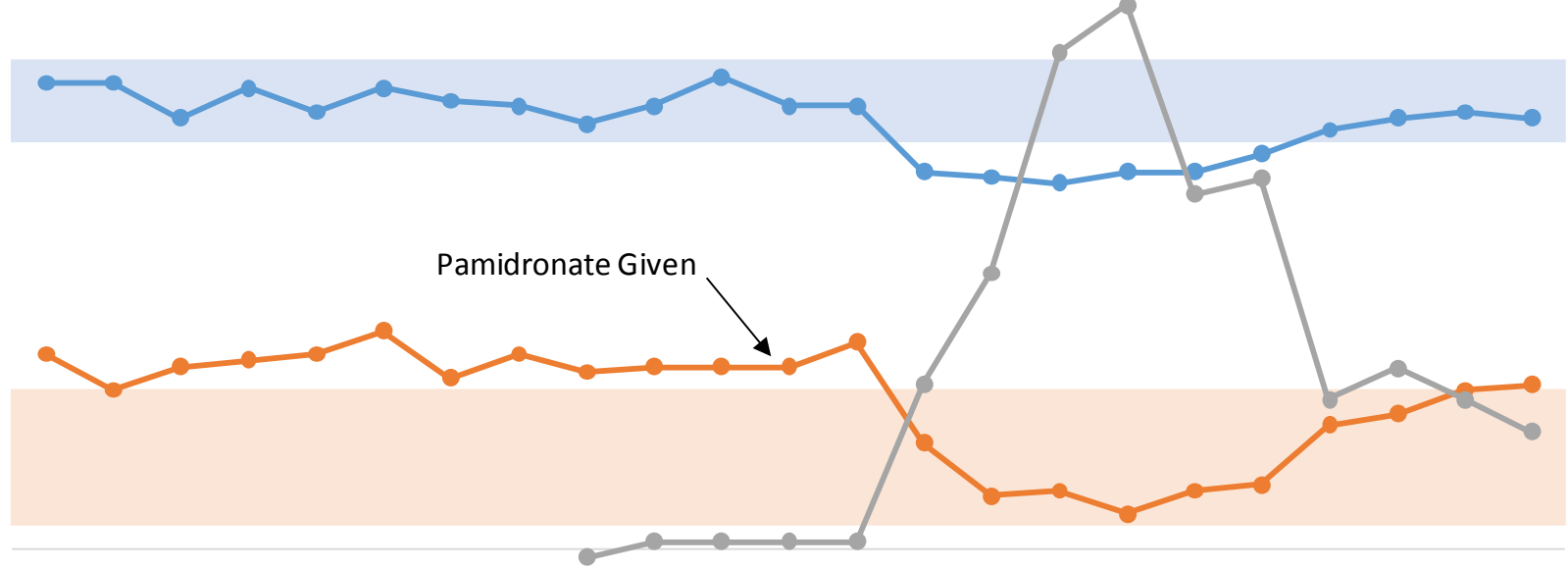

Hospital Day

Figure 1. Comparing levels of calcium, phosphorous and parathyroid hormones prior to and after pamidronate. 